Çukurova Üniversitesi Mühendislik Mimarlık Fakültesi Dergisi, 31(2), ss. 129-137, Aralık 2016

\title{
AHP-WRA Bütünleşik Yöntemi Kullanılarak Mobilya Sektöründe Müşteri Şikayetlerinin Değerlendirilmesi
}

\author{
Cansu DAĞSUYU ${ }^{1}$, Elif Buçe DERE ${ }^{1}$ ve Ali KOKANGÜL ${ }^{* 1}$ \\ ${ }^{1}$ Çukurova Üniversitesi, Mühendislik Mimarlık Fakültesi, Endüstri Mühendisliği Bölümü, \\ Adana
}

Geliş tarihi: 02.06.2016 Kabul tarihi: 23.11.2016

Öz

$\mathrm{Bu}$ çalı̧̧ada mobilya sektöründe yer alan müşteri şikayetleri incelenerek her bir şikayetin önem seviyesi belirlenmiştir. Müşteri şikayetleri şikayetin tipi, açıklaması ve şikayet konusu marka olmak üzere üç ana kritere göre sınıflandırılmıştır. Her bir ana kriterde etkisi olan alt kriterler belirlenmiştir. Müşteriden gelen şikayetlerin önem seviyeleri belirlenirken bu ana ve alt kriterler dikkate alınarak Analitik Hiyerarşi Prosesi ve Ağırlıklı Sıralama Analizi'nden faydalanılmıştır. Böylece müşteri şikayetlerinin önem seviyesi ve dolayısıyla öncelik sırası belirlenmiştir. Elde edilen sonuçlar mobilya alanında faaliyet gösteren firmaların müşteri memnuniyetini maksimum seviyede sağlamak amacıyla yapılacak çalışmalara yön verecektir.

Anahtar Kelimeler: AHP, Müşteri şikayetleri, WRA

\section{Evaluation of Customer Complaints in Furniture Industry by Using Integrated AHP-WRA}

\begin{abstract}
In this study, importance level of complaints has been determined with examination of customer complaints in furniture industry. Customer complaints have been divided and classified in three main criteria as type of complaint; explanation of complaint and brand the complaint subject. Sub criteria, which affect main criteria, have been determined. Importance level of complaints, which are coming from customers, have been analysed with AHP and WRA with the consideration of sub and main criteria. Thus, importance level of customer complaints and their priorities have been specified. Results will help to companies, who are operating in furniture industry, to direct their studies about maximum customer satisfaction.
\end{abstract}

Keywords: AHP, Customer complaints, WRA

\footnotetext{
*Sorumlu yazar (Corresponding author): Ali KOKANGÜL, kokangul@cu.edu.tr
} 


\section{GíRiş}

Teknolojik gelişmelerdeki artış günümüzde firmaları rekabette yeni yollar aramaya zorlamıştır. Teknolojideki gelişimlerin üretim hattına ve ürüne yansıtılması işçilik maliyetlerini ve birim üretim sürelerini azaltmakta ve dolayısıyla üretim miktarını arttırabilmektedir. $\mathrm{Bu}$ durum ürünün satış fiyatının rakiplere göre daha uygun olmasını sağlamaktadır. Gelişmiş teknoloji ile düşük maliyete üretilen ürünün pazarda yer edinebilmesi için ürünün müşteri tarafindan kabul görmesi gerekmektedir. Uygun satış fiyatında kaliteli üretilen ürün Şekil 1'de de görüldüğü gibi beraberinde müşteri memnuniyetini getirmektedir. Memnun müşteri sayesinde müşteri sadakati ve dolayısıyla firmanın ekonomik başarısı artmaktadir.

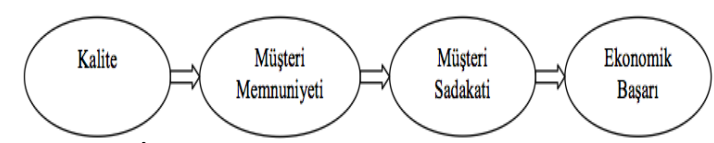

Şekil 1. İşletme başarı zinciri [1]

Müşteri memnuniyetinin sağlanması firmaya fayda sağlarken müşteri memnuniyetsizliği de firmaların hem prestij hem de ekonomik açıdan kayıplar yaşamasına neden olacaktır. Müşteri memnuniyetsizliğinde müşteriler memnuniyetsizliklerini 10 başka kişiye aktarmaktadır. $\mathrm{Bu} 10$ kişinin de \%13'ü bu durumu 20 başka kişiye aktarır [2]. Memnuniyetsizliğin kişiden kişiye aktarılması sonucunda firmanın müşteri gözündeki değeri azalacak ve firma müşteriler tarafindan tercih edilmeyecektir. Ayrıca yeni müşteri kazanmanın maliyeti var olan müşterileri elde tutma maliyetinden çok daha yüksek olduğundan var olan müşterilerin memnuniyetlerinin sağlanması firmalar açısından son derece önem arz etmektedir [3].

Müşteri memnuniyetinin sağlanabilmesi ancak müşteri beklentilerinin karşılanması ve müşteri şikayetlerinin değerlendirilerek giderilmesiyle mümkün olmaktadır. Şikayetlerin değerlendirilmesi ve en kısa sürede giderilmesi çoğu zaman önemli bir iş gücü gerektirmektedir. Birden fazla müşteri şikayeti olması durumunda firmaların işgücünü yönetebilmeleri ve müşteri memnuniyetini maksimize edebilmeleri ancak müşteri şikayetlerinin önem seviyelerinin belirlenmesiyle sağlanabilir.

Müşteri şikayetlerinin veya müşteri memnuniyetlerinin önem seviyelerinin belirlenmesi ile ilgili literatürde bazı çalışmalar bulunmaktadır. Oğuzlar [4] çalışmasında otomotiv sektöründeki müşteri şikayetlerini Analitik Hiyerarşi Prosesi (AHP) ile önceliklendirmiştir. Çalışmada genel şikayetler servis, garanti, ses ve bakım alt başlıklarında; parça şikayetleri ise motor, boya, cam, yağ, fren ve lastik alt başlıklarında incelenmiştir. $\mathrm{Bu}$ alt başliklardan faydalanarak otomobillerin orijinlerine göre değerlendirmesi yapılmıştır. Murat ve Çelik [5] çalışmalarında otellerde müşteri memnuniyet ve sadakatini etkileyen kalite parametrelerini belirlemiş ve AHP ile ikili kryaslamalar yaparak en iyi otel alternatiflerini belirlemiştir. Bhattacharya ve arkadaşları [6] kalite fonksiyon göçerimi uygulamalarında robot seçiminde müşteri beklentilerinin önceliklendirilmesinde AHP yaklaşımından faydalanmıştır. Medjoudj ve arkadaşları [7] çalışmalarında elektrikli enerji sistemlerinde müşteri memnuniyeti ve finansal başarının sağlanması amacıyla AHP tekniğini kullanmıştır. Baliga ve arkadaşları [8], çalışmalarında güneş enerjili 1sıtıcı kullanan müşterilerin memnuniyetlerini arttırmak için, Yıldız ve Yıldız [9], restoranlarda servis kalitesinin arttırılarak müşteri memnuniyetinin sağlanması amaciyla AHP tekniğinden faydalanmıştır. Aksoy [10] çalışmasında tekstil perakende sektöründe müşteri beklentilerinin belirlenmesinde AHP yöntemini kullanmıştır. Elde edilen öncelikleri kalite fonksiyon göçeriminde kullanmıştır. Doğan ve Karakuş [11] çalışmalarında kalite fonksiyon göçeriminde müze ziyaretçilerinin beklentilerinin önem seviyelerini belirlerken AHP yönteminden faydalanmıştır. Urfalığlu ve Tüter [12] müşteri memnuniyetini sağlayacak granit seçiminde AHP yönteminden faydalanmıştır.

Literatürde müşteri memnuniyetinin arttırılmasında AHP tekniğinin kullanıldığı 
pek çok çalışma bulunmaktadır. Bu çalışmada da mobilya sektöründe müşteri memnuniyetinin arttırılması amaciyla müşteri şikayetlerinin giderilmesi konusunda çalışılmıştır. Mobilya sektöründe müşteri şikayeti olabilecek ana ve alt kriterler belirlenmiş ve önem seviyeleri AHP ve Ağırlıklı Sıralama Analizi (Weighted Ranking Analyses-WRA) ile belirlenmiştir.

\section{MATERYAL VE METOT}

\subsection{Materyal}

Müşteri şikayetlerinin belirlenip önceliklendirildiği çalışmamızda mobilya sektöründe hizmet veren bir işletmenin verilerinden faydalanılmıştır. Firmaya gelen müşteri şikayet formları incelenmiş ve müşteri şikayetleri belirlenmiştir. Her bir şikayete ait ürünün markası; şikayetin çağrı tipi ve hata açıklaması kayıt altına alınmıştır.

Firmada üç farklı marka ile çalışmaktadır. Şikayetlerin çağrı tipi; ürün şikayetleri, iade/ değişim talebi, servis hizmet memnuniyetsizliği, servis talebi, işlem gecikmesi / termine uymama ve ücretsiz işlem talebi olmak üzere 6 ana grupta incelenmiştir. Her bir çağrı tipine ait olası nedenler analiz edilmiş ve Çizelge 1 'de verilmiştir.

Mobilya sektöründe hizmet veren firmada hata açıklamaları ürünün lekelenmesi, rahatsız edici olması, kırılması, çökmesi, kumaşta deformasyon, montaj hatası ve servis hatası olmak üzere yedi ana başlıkta özetlenmiştir. Çizelge 2'de her bir hatanın oluşmasının olası nedenleri verilmiştir.

Çizelge 1. Çağrı tiplerinin olası neden analizi

\begin{tabular}{|c|c|}
\hline Çağrı Tipi & Olası Nedenler \\
\hline Ürün Şikayetleri & $\begin{array}{l}\text { 1. Ürünlerde kalitesiz hammadde kullanılması } \\
\text { 2. Gelişen teknolojiye uygun olmaması } \\
\text { 3. Dikkatsizlikten dolayı teslimat sırasında ürüne zarar verilmesi, hasar } \\
\text { oluşması } \\
\text { 4. Farklı boyut, malzeme ve ağırlıklara sahip ürünlerin aynı araçta taşınması } \\
\text { sırasında ürünlerin birbirine zarar vermesi }\end{array}$ \\
\hline $\begin{array}{l}\text { İade/Değişim } \\
\text { Talebi }\end{array}$ & $\begin{array}{l}\text { 1. Üründe telafisi olmayan hataların oluşması } \\
\text { 2. Müşteri beklentilerinin karşılanamaması }\end{array}$ \\
\hline Servis Talebi & $\begin{array}{l}\text { 1. Tüketicinin ürünü yanlış kullanmasına bağlı sorun oluşması } \\
\text { 2. Üretim hatasına bağlı sorun oluşması } \\
\text { 3. Dağıtımdan kaynaklı sorun oluşması }\end{array}$ \\
\hline $\begin{array}{l}\text { İşlem Gecikmesi/ } \\
\text { Termine Uymama }\end{array}$ & $\begin{array}{l}\text { 1. Gelen servis taleplerini karşılayacak elemanın yetersiz olması } \\
\text { 2. Servis elemanlarını ve servis işlerini denetleyici bir sistemin mevcut } \\
\text { olmaması }\end{array}$ \\
\hline $\begin{array}{l}\text { Servis Hizmeti } \\
\text { Memnuniyetsizliği }\end{array}$ & $\begin{array}{l}\text { 1. Servis elemanlarının sorumsuz davranışı } \\
\text { 2. Servis elemanlarının işi standartlara göre yürütememesi }\end{array}$ \\
\hline $\begin{array}{l}\text { Ücretsiz İşlem } \\
\text { Talebi }\end{array}$ & $\begin{array}{l}\text { 1. Tüketicinin üreticiden kaynaklı olduğunu düşündüğü bir sorunun olması } \\
\text { 2. Ürünün tüketiciye teslimatından önceki zaman diliminde hasara uğramış } \\
\text { olması }\end{array}$ \\
\hline
\end{tabular}


Çizelge 2. Hatalar ve olası nedenleri

\begin{tabular}{|l|l|}
\hline Hata Açılaması & Olası Nedenler \\
\hline Leke & $\begin{array}{l}\text { 1. Üretim esnasında leke oluşması } \\
\text { 2. Teslimat esnasında leke oluşması } \\
\text { 3. Depoda stoklama sırasında leke oluşması }\end{array}$ \\
\hline Rahatsız Edici & $\begin{array}{l}\text { 1. Ürün tasarımının ergonomik olmaması } \\
\text { 2. Ürünün üretiminde kullanılan malzemelerin yanlış seçilmesi }\end{array}$ \\
\hline Kırılma & $\begin{array}{l}\text { 1. Tüketicinin kullanımına bağlı ürünün kırılması } \\
\text { 2. Ürün malzemesinin ve/veya boyutlarının yanlış seçilmesinden dolayı ürünün } \\
\text { kırılması }\end{array}$ \\
\hline Çökme & $\begin{array}{l}\text { 1. Ürün malzemesinin yanlış seçilmesi } \\
\text { 2. Üretim hatası }\end{array}$ \\
\hline Kumaşta & $\begin{array}{l}\text { 3. Tüketici hatası Kullanılan kumaşın kalitesinin iyi olmaması } \\
\text { 2. Ürünün kullanım şartlarına bağlı deformasyonu }\end{array}$ \\
\hline Deformasyon & $\begin{array}{l}\text { 1. Servis personelinin kalifiye olmaması } \\
\text { 2. Montaj standartlarının olmaması veya mevcut personelin bu standartlara } \\
\text { dikkat etmemesi }\end{array}$ \\
\hline Montaj Hatası & $\begin{array}{l}\text { 1. Servis elemanının görev bilincinde olmaması } \\
\text { 2. Servis hizmetini kontrol ve/veya iyileştirme sisteminin yetersiz olması }\end{array}$ \\
\hline
\end{tabular}

Çalışmanın yapıldı̆̆ı firma 3 farklı markanın satışını gerçekleştirmektedir. Gizlilik politikası nedeniyle marka isimleri verilmemiş olup çalışmada A, B ve C markaları olarak bahsedilecektir.

\subsection{Metot}

$\mathrm{Bu}$ çalışmada WRA ve AHP yöntemlerinden faydalanılmıştır. WRA yönteminde kriterler belirlenen skalaya göre puanlandırılmaktadır. AHP çok kriterli karar verme yöntemlerinden olup öznel yargiların hesaplamalar sonucunda sayısallaştırmasına dayanmaktadır. AHP yöntemi, Saaty tarafindan 1971-1975 y1lları arasında geliştirilmiştir [13]. Yöntemin adımları şu şekilde özetlenebilir [14]: a. Problemin hiyerarşik bir yapı şeklinde gösterilmesi: Hiyerarşik yapıda amaç, kriterler ve alternatifler bulunmaktadır. Eğer istenirse kriterleri ana ve alt kriterler olmak üzere gruplandırarak hiyerarşik yapının seviyesi arttırılabilir. Şekil 2'de klasik bir hiyerarşik yapı görülmektedir.

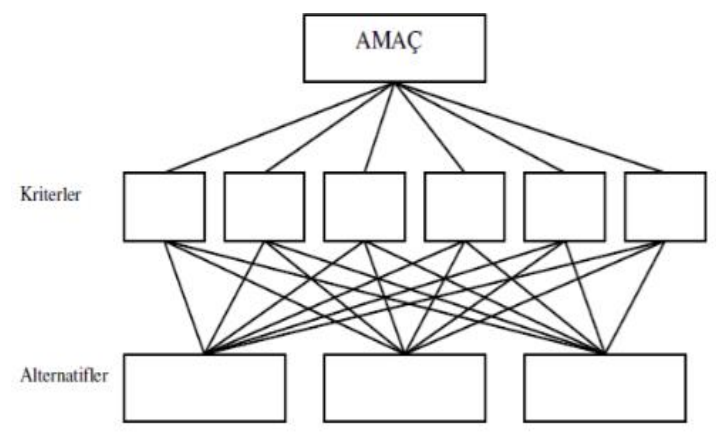

Şekil 2. AHP örnek gösterim 
b. İkili karşılaştırma matrislerinin oluşturulması: İkili karşılaştırmalar yapılırken kriterler kendi aralarında Çizelge 3'deki skala dikkate alınarak karşılaştırılır ve puanlandırılır.

Çizelge 3. AHP skala [15]

\begin{tabular}{|c|l|}
\hline $\begin{array}{c}\text { Önem } \\
\text { Derecesi }\end{array}$ & Tanım \\
\hline 1 & Eşit önem \\
\hline 3 & $\begin{array}{l}\text { Birinin diğerine göre orta derecede } \\
\text { daha önemli olması }\end{array}$ \\
\hline 5 & Güçlü düzeyde önem \\
\hline 7 & Çok güçlü düzeyde önem \\
\hline 9 & Aşırı düzeyde önem \\
\hline $2,4,6,8$ & $\begin{array}{l}\text { İki komşu değer arasındaki değer } \\
\text { (Ortalama Değerler) }\end{array}$ \\
\hline
\end{tabular}

c. İkili karşılaştırma matrislerinin öncelik değerlerinin bulunması: Puanlamanın ardından AHP formülasyonları uygulanarak her bir kriterin ağırlık puanı elde edilir.

d. Tutarlılık oranının hesaplanması: Kriterlerin Çizelge 3'e göre puanlandıktan sonra, her bir satırın geometrik ortalaması alınarak "wi" sütun vektörü oluşturulur. Oluşturulan sütun vektörü normalize edilerek, göreli önemler vektörü " $\mathrm{W}_{i}$ " hesaplanır. Matristeki her bir satırın her bir elemanı göreli önemler vektörü $\left(\mathrm{W}_{\mathrm{i}}\right)$ sütunundaki elemanlarla çarpılıp toplanmasıyla $\mathrm{V}_{1}$ sütun vektörü elde edilir. $\mathrm{V}_{1}$ sütun vektörünün her elemanı, $\mathrm{W}_{\mathrm{i}}$ vektöründe karş1 gelen elemana bölünür ve $V_{2}$ vektörü hesaplanır. $V_{2}$ sütun vektörünün aritmetik ortalaması alınarak da en büyük öz değer $\lambda_{\text {max }}$ elde edilir. $n$ dikkate alınan kriter sayısı olmak üzere tutarlılık göstergesi ve tutarlılık oranı sirasiyla Denklem 1 ve Denklem 2 ile elde edilir [15].

Tutarlılık Göstergesi $=\frac{\lambda_{\max }-\mathrm{n}}{\mathrm{n}-1}$
Tutarlılık Oranı $=\frac{\text { Tutarlılık Göstergesi }}{\text { Rassallık Göstergesi }}$

Rassallık göstergesi (RG) ana kriter sayısına göre değişmektedir. Çizelge 4'de rassallık gösterge değerleri verilmiştir.

Çizelge 4. Kriter sayısına göre rassal indeks değerleri [16]

\begin{tabular}{|c|c|c|c|}
\hline $\mathbf{n}$ & $\mathbf{R G}$ & $\mathbf{n}$ & $\mathbf{R G}$ \\
\hline $\mathbf{3}$ & 0,5245 & $\mathbf{9}$ & 1,4499 \\
\hline $\mathbf{4}$ & 0,8815 & $\mathbf{1 0}$ & 1,4854 \\
\hline $\mathbf{5}$ & 1,1086 & $\mathbf{1 1}$ & 1,5141 \\
\hline $\mathbf{6}$ & 1,2479 & $\mathbf{1 2}$ & 1,5365 \\
\hline $\mathbf{7}$ & 1,3417 & $\mathbf{1 3}$ & 1,551 \\
\hline $\mathbf{8}$ & 1,4056 & $\mathbf{1 4}$ & 1,5713 \\
\hline
\end{tabular}

Tutarlılık Oranı 0,10'a eşit ya da 0,10'dan küçük ise yapılan ikili karşılaştırmalar tutarlıdır yorumu yapılabilir. Tutarlılık Oranı 0,10'dan büyük olduğunda tutarlılık yoktur ve bu durumda puanlamayı yapan uzmanlara AHP puanlamasının tekrar yaptırılması gerekebilmektedir.

e. Nihai öncelik değerlerinin belirlenmesi: Hiyerarşinin en üstünden en altına doğru adım adım her bir seviyede yer alan ağırlıklar çarpılır ve bu çarpımlar toplanarak her bir alternatifin nihai öncelik değeri elde edilir.

Firmaya gelen müşteri şikayetlerinin önceliklendirilmesinde çağrı tipi, hata açıklaması ve marka ana kriterler olarak alınmış ve ana kriterlerin önem seviyeleri AHP yöntemi ile belirlenmiştir. AHP yönteminde kullanılan skala Çizelge 3'te verilmiştir. Her bir ana kriterde bulunan alt kriterlerin puanlandırılmasında ise WRA tekniğinden faydalanılmıştır. WRA tekniğinde Çizelge 5'de bulunan 1-5'lik skala kullanılmıştır. Her bir ana kriterin önem seviyesi ile alt kriterlerin puanları çarpılarak ağırlıklı puanlar elde edilmektedir. Elde edilen toplam puana göre de sıralama yapılarak müşteri şikayetlerinin öncelik sırası belirlenmiştir. 
Çizelge 5. WRA skala

\begin{tabular}{|c|l|}
\hline Puan & Açıklama \\
\hline 1 & Çok az önemli \\
\hline 2 & Az önemli \\
\hline 3 & Orta önemli \\
\hline 4 & Önemli \\
\hline 5 & Çok önemli \\
\hline
\end{tabular}

\section{BULGULAR VE TARTIŞMA}

Çalışmada dikkate alınan çağrı tipi, hata açıklaması ve marka ana kriterlerinin ağırlıkları belirlenirken uzman görüşü doğrultusunda AHP ile puanlama yapılmıştır. Çalışmada uygulanan AHP adımları aşağıda verilmiştir.

a. Problemin hiyerarşik bir yapı şeklinde gösterilmesi: Çalışmada uygulana AHP hiyerarşisi Şekil 3'de verilmiştir. Müşteri şikayetlerinin önceliklerinin belirlenmesi çalışmada amaçlanmaktadır. Müşteri şikayetleri 'alternatifler'i oluşturmaktadır. Şikayetlerin önceliklendirilmesinde WRA tekniği ile entegre bir yöntem izleneceğinden hiyerarşide alternatiflere yer verilmemiştir.

b. İkili karşılaştırma matrislerinin oluşturulması: Ana kriterlerin ikili karşılaştırma matrisine Çizelge 6'da yer verilmiştir. Alt kriterlerin önem seviyelerinin belirlenmesinde WRA tekniğinden faydalanılmıştır. c. İkili karşılaştırma matrislerinin öncelik değerlerinin bulunması: İkili karşılaştırmalar sonucunda her bir ana kriterin önem seviyeleri Çizelge 6'da son kolonda ağırlık değerleri olarak verilmiştir. Bu çalışmada alt kriterlerin önem değerleri bulunurken WRA tekniği kullanılmıştır. Çizelge 5'de verilen WRA skalasına göre puanlama yapılmış ve puanlamalar Çizelge 7'de verilmiştir.

d. Tutarlılık oranının hesaplanması: Denklem 1 ve Denklem 2 için $n=3$ alınarak hesaplamalar yapıldığında tutarlılık Göstergesi= 0,026810788; Tutarlılık Oranı $=0,051559208$ olarak bulunmaktadır. Tutarlılık Oranı 0.10'dan küçük olduğu için yapılan puanlamanın tutarlı olduğu söylenebilir.

e. Nihai öncelik değerlerinin belirlenmesi: Ana kritlerlerin WRA'da kullanılacak olan ağırlıkları AHP ile belirlenmiş ve her bir alt parametrelerin 1-5 skalasına ait puanları uzman görüşü ile ortaya konulmuştur. Firmaya gelen müşteri şikayetlerinin önem seviyeleri belirlenip önceliklendirilirken Çizelge 6'daki ve Çizelge 7'deki puanlar kullanılmaktadır. Ana ve alt kriterlerin ağırlıkları Şekil 3'de verilmiştir.

Alternatifleri oluşturulan müşteri şikayetlerinin önceliklendirilmesinde firmaya gelen müşteri şikayetlerinin beş tanesi dikkate alınmış ve Çizelge 8'de verilmiştir.

Çizelge 6. Ana kriterlerin AHP değerlendirmesi

\begin{tabular}{|l|c|c|c|c|}
\hline Parametreler & Marka & Çağrı Tipi & Hata Açıklaması & Ağırlık Değerleri \\
\hline Marka & 1 & $1 / 3$ & $1 / 3$ & 0,15 \\
\hline Çağrı Tipi & 3 & 1 & 2 & 0,52 \\
\hline Hata Açıklaması & 3 & $1 / 2$ & 1 & 0,33 \\
\hline
\end{tabular}

Çizelge 7. Alt parametrelerin puanlandırılması

\begin{tabular}{|l|c|l|c|l|c|}
\hline Çağrı Tipi & Puan & Hata Açıklaması & Puan & Marka & Puan \\
\hline Ürün Şikayetleri & 4 & Leke & 3 & Marka A & 5 \\
\hline İade/Değişim Talebi & 5 & Rahatsız Edici & 5 & Marka B & 4 \\
\hline Servis Talebi & 3 & Kırılma & 4 & Marka C & 5 \\
\hline İşlem Gecikmesi/Termine Uymama & 5 & Çökme & 5 & & \\
\hline Servis Hizmeti Memnuniyetsizliği & 5 & Kumaşta Deformasyon & 2 & & \\
\hline Ücretsiz Servis Talebi & 2 & Montaj Hatası & 4 & & \\
\hline & & Servis Hatası & 4 & & \\
\hline
\end{tabular}




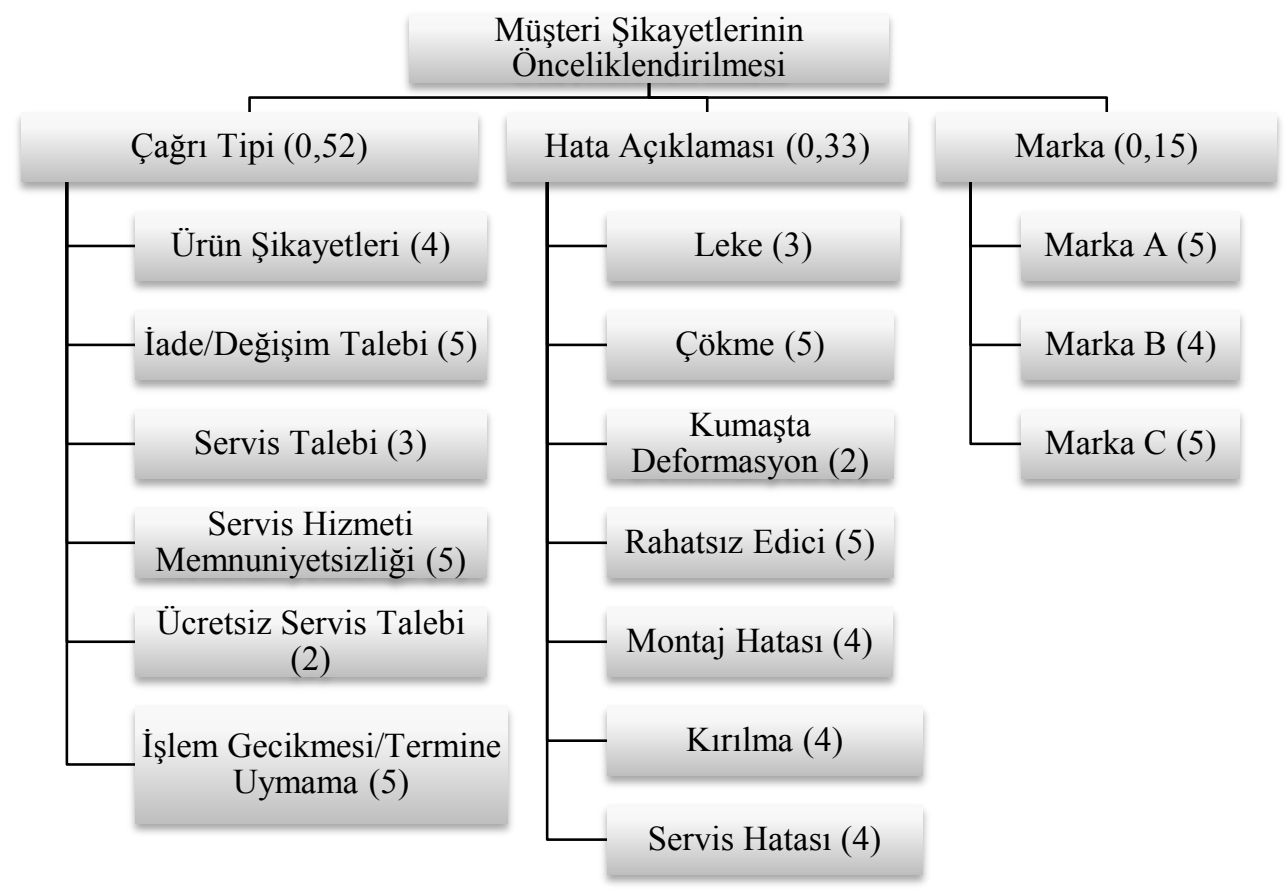

Şekil 3. AHP hiyerarşik yapı

Çizelge 8. Firmaya gelen müşteri şikayetleri

\begin{tabular}{|l|l|l|l|}
\hline Şikayet No & Marka & Çağrı Tipi & Hata \\
\hline Ş(1) & Marka A & İade/Değişim Talebi & Leke \\
\hline Ş(2) & Marka B & Ürün Şikayetleri & Rahatsı Edici \\
\hline Ş(3) & Marka A & Servis Talebi & Montaj Hatası \\
\hline Ş(4) & Marka C & Ücretsiz İşlem Talebi & Leke \\
\hline Ş(5) & Marka B & Ürün Şikayetleri & Çökme \\
\hline
\end{tabular}

Çizelge 8'de dikkate alınan şikayetleri AHP ve WRA tekniğine göre derecelendirme sonuçları Çizelge 9'da verilmiştir. Çizelge 9'da ikinci kolonda ana kriterler için AHP'den elde edilen ağırlık puanlarına (AP) yer verilmiştir. Her bir şikayetin sınıfına göre Çizelge 7'deki puanlandırmaya göre aldığı puanlar ve bu puanların ait oldukları parametrelerin AHP ağırlık puanları ile çarpımı 'Ağırlıklı Şikayet Puanı (AŞP)'na da Çizelge 9'da yer verilmiştir. Çizelge 9'un son satırında da her bir şikayetin ağırlıklı toplam puanları elde edilmiştir.
Şikayetlerin AHP ve WRA tekniklerine göre önceliklendirilmesi Çizelge 9'dan incelendiğinde en yüksek puanı 2 numaralı şikayete aittir. $\mathrm{Bu}$ nedenle şikayetlerin giderilmesinde ilk olarak 2 numaralı şikayete öncelik verilecek ve firmada bulunan personelin ve alet-ekipmanın bu şikayetin çözümünde kullanılması sağlanmaya çalışılacaktır. Çizelge 9'da yapılan değerlendirmeye göre 2 numaralı şikayetin giderilmesinin ardından sırasıyla $1,5,3$ ve 4 numaralı şikayetlerin çözülmesi gerekmektedir. 
Çizelge 9. Müşteri şikayetlerinin nihai puanlaması

\begin{tabular}{|c|c|c|c|c|c|c|c|c|c|c|c|}
\hline Parametre & $\mathbf{A P}$ & Ş (1) & $\begin{array}{c}\text { AŞP } \\
\text { (1) }\end{array}$ & Ş (2) & $\begin{array}{c}\text { ASSP } \\
\text { (2) }\end{array}$ & Ş (3) & $\begin{array}{c}\text { AŞP } \\
\text { (3) }\end{array}$ & Ş (4) & $\begin{array}{c}\text { AŞP } \\
\text { (4) }\end{array}$ & Ş (5) & $\begin{array}{c}\text { AŞP } \\
\text { (5) }\end{array}$ \\
\hline Marka & 0,15 & 5 & 0,75 & 5 & 0,75 & 5 & 0,75 & 4 & 0,6 & 4 & 0,6 \\
\hline Çağrı Tipi & 0,52 & 5 & 2,6 & 4 & 2,08 & 3 & 1,56 & 2 & 1,04 & 4 & 2,08 \\
\hline Hata & 0,33 & 3 & 0,99 & 5 & 1,65 & 4 & 1,32 & 3 & 0,99 & 5 & 1,65 \\
\hline Toplam & & & 4,34 & & 4,48 & & 3,63 & & 2,63 & & 4,33 \\
\hline
\end{tabular}

\section{SONUÇLAR VE ÖNERILLER}

Çalışmada mobilya sektöründe teknik servis hizmeti veren bir firmaya gelen müşteri şikayetleri değerlendirilmiş ve şikayetlerin önceliklendirilmesi yapılmıştır. Firmadaki olası şikayetler tip, hatalar ve marka olmak üzere 3 ana kriter ile incelenmiş ve ana kriterler AHP ile ağırlıklandırılmıştır. Firmaya gelen şikayetlerin alt kriterlerden alacağ 1 puanlar WRA ile belirlenmiş ve şikayetlerin WRA puanları AHP puanları ile çarpılarak şikayetlerin ağırlıklı puanları elde edilmiştir. $\mathrm{Bu}$ ağırlıklı puanlara göre hangi şikayetin öncelikli olarak çözülmesinin firmaya maksimum faydayı getireceği ortaya konulmuştur.

Bu çalışma sonucunda firma aynı anda birden fazla müşteri şikayeti ile karşılaştığında mevcut personel ve alet-ekipman kapasitesini daha etkin yönetebilecektir. Firma için öncelikli müşteri şikayetinin en hızlı şekilde çözüme kavuşturulması müşteri memnuniyetini de arttıracağından firmanın kar marjını ve pazardaki rekabet gücünü de artıracaktır.

\section{KAYNAKLAR}

1. Türkyılmaz, A., Özkan, C., 2005. Ulusal Müşteri Memnuniyet İndeksleri. In KalDer Forum, 16, 73-77.

2. Gerson, F. R., 1997. Müşteri Tatmininde Süreklilik. (Çev: Tülay Savaşer). Rota Yayınları, İstanbul.

3. Burucuoğlu, M., 2011. Müşteri Memnuniyeti ve Sadakatini Arttırmada Müşteri Şikayetleri Yönetiminin Etkinliği: Bir Örnek Olay İncelemesi, Yüksek Lisans Tezi, Karamanoğlu Mehmetbey Üniversitesi.
4. Oğuzlar, A., 2007. Analitik Hiyerarşi Süreci İle Müşteri Şikayetlerinin Analizi. Akdeniz University Faculty of Economics \& Administrative Sciences Faculty Journal/Akdeniz Universitesi İktisadi ve İdari Bilimler Fakültesi Dergisi, 7(14).

5. Murat, G., Çelik, N., 2007. Analitik Hiyerarşi Süreci Yöntemi ile Otel İşletmelerinde Hizmet Kalitesini Değerlendirme: Bartın Örneği. Uluslararası Yönetim İktisat ve İşletme Dergisi, 3(6), 1-20.

6. Bhattacharya, A., Sarkar, B., Mukherjee, S. K., 2005. Integrating AHP with QFD for Robot Selection under Requirement Perspective. International Journal of Production Research, 43(17), 3671-3685.

7. Medjoudj, R., Laifa, A., Aissani, D., 2012. Decision Making on Power Customer Satisfaction and Enterprise Profitability Analysis Using the Analytic Hierarchy Process. International Journal of Production Research, 50(17), 4793-4805.

8. Baliga, A.J., Rodrigues, L.L., Shiva Prasad, H.C., 2015. Prioritising The Sub Criterions to Gauge Customer Satisfaction Levels of Solar Water Heater Users Using AHP Approach. International Journal of Current Research and Review, 7(5), 16311-16317.

9. Yıldiz, S., Y1ldiz, E., 2015. Service Quality Evaluation of Restaurants Using The AHP And Topsis Method. Journal of Social and Administrative Sciences, 2(2), 53-61.

10. Aksoy, A., Hazır Giyim Perakende Sektöründe İçsel Kıyaslama Çalışmasına Bir Örnek, Yüksek Lisans Tezi, İstanbul Teknik Üniversitesi, 2013.

11. Doğan, N. Ö., Karakuş, Y., 2014. KFG-AHP Bütünleşik Yöntemi Kullanılarak Turizm Sektöründe Hizmet Kalitesinin 
Değerlendirilmesi: Göreme Açık Hava Müzesi Üzerine Bir Uygulama, Suleyman Demirel University Journal of Faculty of Economics \& Administrative Sciences, 19(3).

12. Urfalığlu, F., Tüter, K., 2015. Analitik Hiyerarşi Yöntemi İle Müşteri Memnuniyeti Açısından Uygun Granitin Seçimi Üzerine Bir Uygulama, Marmara Üniversitesi İ.İ.B. Dergisi, 1, 233-260.

13. Saaty, R.W., 1987. The Analytic Hierarchy Process: What it is and How it is Used, Mathl Modelling, 9(3-5): 161-176.

14. Vaidya, O.S., Kumar, S., 2006. Analytic Hierarchy Process: An Overview of Applications, European Journal of Operational Research, 169: 1-29.

15. Saaty, T.L., 1980. The analytic hierarchy process. New York: McGraw Hill. International, Translated to Russian, Portuguese, and Chinese, Revised editions, Paperback (1996, 2000), Pittsburgh: RWS Publications.

16. Alonso, J.A., Lamata, M.T., 2006. Consistency in the Analytic Hierarchy Process: A New Approach, International Journal of Uncertainty, Fuzziness and Knowledge-Based Systems, 14(4): 445-459. 
